\title{
Clinical Toxicology and Overdose of Psychiatric Medications
}

\author{
YC Chan
}

\begin{abstract}
This article reviews the poisoning epidemiology in Hong Kong, assessment and treatment of acute poisoning, and management of acute psychiatric medication overdose. In 2016, nearly 4000 poisoning cases involving approximately 6000 poisons were reported to Hong Kong Poison Information Centre. About $25 \%$ of the poisons involved were psychiatric-related medications. The initial medical assessment on poisoning includes history taking, vital signs monitoring, and focused physical examination. Approaches in managing acute poisoning include supportive measures, decontamination, antidote use, and enhanced elimination. Management on overdose of psychiatric medications (zopiclone, tricyclic antidepressants, selective serotonin reuptake inhibitor, antipsychotics, valproic acid, lithium, and methylphenidate) are discussed with practical tips highlighted.
\end{abstract}

Key words: Drug overdose; Poisoning; Toxicology

Yiu Cheung Chan, MBBS, FRCS(Edin), FHKCEM, FHKAM (Emergency Medicine), Consultant, Accident \& Emergency Department, Hong Kong Poison Information Centre, United Christian Hospital, Hong Kong

Address for correspondence: Dr Yiu Cheung Chan, Accident \& Emergency Department, Hong Kong Poison Information Centre, United Christian Hospital, Hong Kong.

Email:chanyc3@ha.org.hk

Submitted: 1 March 2018; Accepted: 25 June 2018

\section{Introduction}

Clinical toxicology has been recognised as a specialty in Hong Kong since 2016. ${ }^{1}$ Clinical toxicology involves the treatment and prevention of poisoning with emphasis on diagnosis, evaluation, and management of patients after exposure to toxic agents. Psychiatrists may encounter patients with clinical toxicology involving psychiatric medication overdose, acute and chronic toxicity of abusive substances, and psychiatric assessment of acute poisoned patients. This article reviews the poisoning epidemiology in Hong Kong, assessment and treatment of acute poisoning, and management of acute psychiatric medication overdose.

\section{Epidemiology}

The Hong Kong Poison Information Centre (HKPIC) provides a 24-hour phone consultation service (Tel: 2772 2211) to healthcare professionals in Hong Kong for poison information and management advice. HKPIC also collects important poisoning epidemiological data in Hong Kong from the Hospital Authority. ${ }^{2}$ In the HKPIC annual report 2016, nearly 4000 poisoning cases involving approximately 6000 poisons were reported. Approximately $25 \%$ of these poisons were psychiatric-related medications including hypnotics, antidepressants, antipsychotics, valproic acid, and lithium. The three commonest reasons for poisoning were suspected self-harm (mostly associated with psychiatric illness), unintentional exposure, and substance abuse. Most patients were managed with supportive measures, but $14 \%$ were treated with decontamination and $13 \%$ received antidotes. Approximately $1 \%$ of the cases resulted in death and $4 \%$ resulted in severe adverse effects; $84 \%$ resulted in mild or no adverse effects. ${ }^{3}$

\section{Assessment of acute poisoning}

The initial medical assessment on poisoning or suspected poisoning includes history taking, vital signs monitoring, and focused physical examination. The clinical approach to poisoning emphasises treating the patient rather than treating the poison. History taking can provide details on "what, when, where, why, and how" the poison was exposed to the patient. If the patient develops symptoms, "what, when, and how is it progressing" will provide useful clinical information. Any interventions and associated responses are also important. However, the history may be incomplete, unreliable, or even unobtainable. Even if available, the history should be interpreted with caution and cross-checked with information from other sources and clinical presentation, especially in patients with known psychiatric illness, suicidal attempt, or malicious poisoning.

Assessment of vital signs is important for recognising toxidrome (toxic syndrome), monitoring clinical progress, and guiding intervention and treatment. Many poisons affecting the autonomic nervous system affect the vital signs via the sympathetic and/or parasympathetic pathway. Assessing and monitoring vital signs must be interpreted with consideration of each patient's physiological, 
psychiatric, and premorbid conditions. For example, a systolic blood pressure of $100 \mathrm{~mm} \mathrm{Hg}$ may be normal in a young healthy woman, but it may imply shock in an old man with known hypertension. Tachycardia may indicate drug toxicity, but it is not uncommon in patients with anxiety or schizophrenia. Serial monitoring of changes in vital signs is more informative than interpretation of vital signs at a particular time point, especially in the early phase of poison exposure. Some important/common poisons in Hong Kong that may cause vital sign abnormalities are listed in Table 1.

A toxicological physical examination helps recognise unidentified poison exposure or other alternative medical causes. It should include mental status (Glasgow Coma Scale or Alert Verbal Painful Unresponsiveness Scale), pupil size and reaction, skin colour and condition, bowel sound, urinary bladder distension, muscle power, tone and jerks, and the organ systems of interest with respect to the exposed poison.

\section{Treatment of acute poisoning}

Approaches in managing acute poisoning include supportive measures, decontamination, antidote use, and enhanced elimination. Supportive measures include stabilising the airway, breathing, and circulation; monitoring vital signs, expected toxicity, and its progress; using oxygen, dextrose, intravenous fluid, and other symptomatic treatment as clinically indicated; and applying good nursing care and preventing of secondary injury. Most poisoning cases respond well to a good supportive care alone. The routine use of naloxone or flumazenil in comatose patients with suspected poisoning is no longer recommended.

The considerations for decontamination include whether the poison can be removed from the body before absorption, the amount of poison absorbed, and the expected subsequent morbidity and mortality. Humans are typically exposed to poisons via three major routes: oral ingestion, inhalation, and dermal contact. For inhalational exposure, no decontamination method is clinically practicable apart from removal of the source to prevent further exposure. For dermal contact, surface decontamination with copious amount of water is most effective. For poison ingestion, methods of gastrointestinal (GI) decontamination include gastric lavage ${ }^{4}$ single-dose activated charcoal, ${ }^{5}$ multipledose activated charcoal, ${ }^{6}$ whole bowel irrigation, ${ }^{7}$ and rarely surgical intervention such as endoscopic removal or gastrostomy. In Hong Kong, about $15 \%$ of poisoning cases are treated with GI decontamination mostly by oral administration of activated charcoal. ${ }^{3}$ High-level evidence on GI decontamination is limited..$^{8,9}$ Most mild poisoned patients can be managed satisfactorily by supportive measures alone. Certain types of poisoned patients can benefit from GI decontamination. The decision for GI decontamination must be based on the situation and made by a sufficiently experienced clinician.

Antidotes act through kinetic or dynamic interaction with the poison. The timely and appropriate use of antidotes can be life-saving in situations such as cyanide poisoning. However, not all poisons have antidotes, and for those that do it is impractical for a hospital to stock all antidotes. The list of antidotes is long, ranging from commonly used drugs such as atropine to rarely used and expensive drugs such as fomepizole. The Hospital Authority stocks a wide variety of antidotes at three levels based on the frequency of use, urgency of administration when indicated, the presence of alternative antidotes, and cost-effectiveness. From 2012 to 2016 , an average of $13 \%$ of acute poisoned patients were given antidotes as treatment. ${ }^{3}$ The commonly used antidotes were $\mathrm{N}$-acetylcysteine, benzodiazepine, naloxone, antivenoms, calcium chloride/gluconate, and sodium bicarbonate.

Enhanced elimination should be considered in the following conditions: life-threatening clinical toxicity, dose exposed and/or blood concentration indicating likely severe morbidity or mortality, impaired normal route of elimination, and failure to respond to maximal supportive

Table 1. Vital sign abnormalities and their causative poisons

\begin{tabular}{|ll|}
\hline $\begin{array}{l}\text { Vital sign } \\
\text { abnormality }\end{array}$ & Important/common causative poisons \\
Hypotension & Aconite, antidepressant (tricyclic), beta-blocker, calcium channel blocker, opioid \\
\hline Hypertension & Sympathomimetic (methamphetamine, cocaine, ketamine), nicotine, tramadol \\
\hline Bradycardia & Aconite, beta-blocker, calcium channel blocker, cardiac active steroids, ciguatera \\
\hline Tachycardia & Aconite, anticholinergic, antidepressant, antihistamine, sympathomimetic \\
\hline Bradypnoea & Opioid, sedative, clonidine, organophosphate, gelsemium \\
\hline Tachypnoea & Salicylate, methylxanthines, respiratory irritants, methaemoglobin-inducers, sympathomimetic \\
\hline Hypothermia & Opioid, sedative, ethanol, hypoglycaemic agents \\
\hline Hyperthermia & $\begin{array}{l}\text { Sympathomimetic, anticholinergic, salicylate, serotonin syndrome, neuroleptic malignant } \\
\text { syndrome }\end{array}$ \\
\hline
\end{tabular}


measures. Methods of enhanced elimination include oral administration of multiple-dose activated charcoal, urinary alkalinisation or extracorporeal treatments such as haemodialysis, haemoperfusion, or haemofiltration. ${ }^{10}$

\section{Management on overdose of psychiatric medications}

\begin{abstract}
Zopiclone
Zopiclone is the fifth commonest poison encountered in HKPIC in 2016. ${ }^{3}$ Zopiclone is a cyclopyrrolone derivative, which is a central $\mathrm{GABA}_{\mathrm{A}}$ receptor agonist with clinical effects similar to benzodiazepines. Prescription is required, but it is not uncommon to obtain it from local pharmacy without prescription. Central nervous system (CNS) depression is the most common overdose effect. Other features include ataxia, dysarthria, and mild respiratory depression with occasional hypotension. In most cases, supportive measures are sufficient, and intubation or mechanical ventilation is rarely needed. Most cases recovered within 12 to 24 hours. Massive overdose (typically $>50$ tablets or $375 \mathrm{mg}$ ) may cause methaemoglobinaemia, haemolysis, and renal impairment. The onset of renal impairment and haemolysis is usually within 1 to 3 days, whereas methaemoglobinaemia usually appear within 24 hours. ${ }^{11}$ In addition to supportive measures and GI decontamination, flumazenil can be used to revere the CNS depression. Flumazenil is the classical antidote for benzodiazepine and acts as a competitive benzodiazepine receptor antagonist. It can be considered in selected cases of zopiclone poisoning in which benefit of coma reversal outweighs its risk. ${ }^{12}$ For the treatment of zopiclone-induced methaemoglobinaemia, methylene blue at the conventional dose of $1-2 \mathrm{mg} / \mathrm{kg}$ body weight can be used.
\end{abstract}

\section{Tricyclic antidepressants}

Tricyclic antidepressants (TCAs) remain a common cause of poisoning-related morbidity and mortality despite their decreasing use. HKPIC recorded 52 cases of TCA poisoning in 2016. ${ }^{3}$ Commonly used TCAs include amitriptyline, dothiepin, imipramine, and nortriptyline. Its toxicity is significant in acute overdose of $>10-20 \mathrm{mg} / \mathrm{kg}$ body weight in adults or $>5 \mathrm{mg} / \mathrm{kg}$ body weight in children. Cardiac toxicity, CNS toxicity, and anticholinergic toxidrome typically occur within 1-2 hours of ingestion. Cardiac toxicities include hypotension and wide complex tachyarrhythmia. CNS toxicities include lethargy, confusion to deep coma, and seizure. Seizure can occur abruptly and is found in $>5 \%$ of the cases. Clinical deterioration can be rapid and close monitoring is recommended. Electrocardiography is mandatory; characteristic findings include sinus tachycardia, widen QRS duration (>100 ms), and terminal 40-ms rightaxis deviation. QRS duration (the maximum $\mathrm{QRS}$ recorded in limb leads) is better predictor of clinical effects than TCA levels. ${ }^{13}$ Brugada electrocardiographic pattern is uncommon $(<3 \%)$ and is associated with increased risk of seizures, widened QRS, and hypotension. ${ }^{14}$ Early and adequate serum alkalisation by rapid sodium bicarbonate infusion can be life-saving in patients with TCA cardiac toxicity. In addition to good supportive care with intensive monitoring, GI decontamination including gastric lavage and single- or multiple-dose activated charcoal should be considered. The use of physostigmine and flumazenil is contraindicated. For life-threatening poisoning not responsive to standard treatment, clinical toxicologist should be consulted for treatment options such as intravenous lipid emulsion ${ }^{15,16}$ and high-dose insulin. ${ }^{17}$ Extracorporeal treatment is not recommended for TCA poisoning. ${ }^{18}$

\section{Selective serotonin reuptake inhibitor}

Selective serotonin reuptake inhibitor (SSRI) is a safer antidepressant than TCAs with lower lethality. ${ }^{19}$ In overdose cases, severe toxicity is unlikely except for citalopram that may cause seizure, prolonged QTc, and subsequently torsade de pointes. Common symptoms after acute overdose of SSRI include nausea, vomiting, tachycardia, dizziness, and lethargy. Life-threatening symptoms (coma, seizure, and severe arrhythmia) are rare. Up to $14 \%$ of SSRI overdose cases develop serotonin syndrome of varying severity. ${ }^{20}$ Supportive care and GI decontamination by activated charcoal are the mainstay treatment. A longer observation period ( $\geq 24$ hours) is recommended for citalopram overdose owing to the possibility of delayed toxicity. Sodium bicarbonate and magnesium can be used to treat citalopram-induced prolonged QRS and QTc, respectively. Treatment for serotonin syndrome involves serotonergic drugs disuse and supportive measures including adequate hydration and cooling. Titrated dose of benzodiazepine and the use of neuromuscular blockade may be necessary for refractory hyperthermia and increased muscle activity. Cyproheptadine, an antihistamine with $5 \mathrm{HT}_{1 \mathrm{~A}}$ and $5 \mathrm{HT}_{2}$ receptor antagonism, can be used at an initial dose of 8-12 $\mathrm{mg}$ as a treatment for serotonin syndrome. ${ }^{21}$

\section{Antipsychotic}

Antipsychotic therapeutic mechanism appears to be related to central dopamine receptor antagonist potency and serotonin receptor blocking activity. Different antipsychotics have other receptors / ion channel activities. Table 2 summarises the toxicity of antipsychotic and its evaluation and management. CNS and cardiovascular toxicities are the main concerns. CNS depression or sedation ranges from somnolence to coma, being more prominent in naïve or paediatric patients. Seizure is not common. Extrapyramidal symptoms include acute dystonia and rarely neuroleptic malignant syndrome. Hypotension is caused by alpha-adrenergic blockade, and sinus tachycardia occurs reflexively to hypotension or owing to antimuscarinic effects. Sodium channel blocking results in prolonged QRS in electrocardiography, conduction abnormalities, and myocardial depression. QTc interval prolongation is usually due to the blockade of the delayed rectifier potassium channel. Supportive measures are the mainstay treatment, and airway protection is needed for deeply sedated patients. 
Table 2. Antipsychotic toxicity and its evaluation and management

\begin{tabular}{|c|c|c|c|c|c|c|}
\hline $\begin{array}{l}\text { Receptor } \\
\text { antagonism / } \\
\text { channel } \\
\text { blockage }\end{array}$ & Dopamine & $\begin{array}{l}\text { Alpha } \\
\text { adrenergic }\end{array}$ & Muscarinic & Histamine & $\begin{array}{l}\text { Sodium }(\mathrm{Na}+) \\
\text { channel }\end{array}$ & $\begin{array}{l}\text { Potassium }(\mathrm{K}+) \\
\text { channel }\end{array}$ \\
\hline $\begin{array}{l}\text { Toxicity / } \\
\text { adverse effect }\end{array}$ & $\begin{array}{l}\text { Extrapyramidal } \\
\text { symptoms }\end{array}$ & $\begin{array}{l}\text { Hypotension, } \\
\text { reflex } \\
\text { tachycardia }\end{array}$ & $\begin{array}{l}\text { Anticholinergic, } \\
\text { toxidrome }\end{array}$ & Sedation & $\begin{array}{l}\text { QRS-widening, } \\
\text { hypotension }\end{array}$ & $\begin{array}{l}\text { QT-prolongation, } \\
\text { torsade de pointes }\end{array}$ \\
\hline Evaluation & $\begin{array}{l}\text { Vital signs, } \\
\text { physical } \\
\text { examination }\end{array}$ & $\begin{array}{l}\text { Vital signs, } \\
\text { physical } \\
\text { examination }\end{array}$ & $\begin{array}{l}\text { Vital signs, } \\
\text { physical } \\
\text { examination }\end{array}$ & $\begin{array}{l}\text { Vital signs, } \\
\text { physical } \\
\text { examination }\end{array}$ & $\begin{array}{l}\text { Electro- } \\
\text { cardiography }\end{array}$ & $\begin{array}{l}\text { Electro- } \\
\text { cardiography }\end{array}$ \\
\hline Interventions & $\begin{array}{l}\text { Diphenhydramine, } \\
\text { treatment for } \\
\text { neuroleptic } \\
\text { malignant } \\
\text { syndrome }\end{array}$ & $\begin{array}{l}\text { Intravenous } \\
\text { fluids, pressor / } \\
\text { inotropes }\end{array}$ & Supportive care & $\begin{array}{l}\text { Supportive } \\
\text { care }\end{array}$ & $\mathrm{Na}+\mathrm{HCO} 3-$ & $\begin{array}{l}\text { Intravenous } \\
\text { magnesium, } \\
\text { correct } \\
\text { electrolytes }\end{array}$ \\
\hline
\end{tabular}

Hypotension and tachycardia generally respond well to intravenous fluid. Inotrope or vasopressor may be needed in severe cases. Sodium bicarbonate and magnesium are indicated for prolonged QRS and QTc, respectively. Anticholinergic drug can be administered for acute dystonia. For management of neuroleptic malignant syndrome, adequate cooling, muscle relaxation by benzodiazepines or paralytic agents, dopamine agonists such as bromocriptine and dantrolene can be considered..$^{22}$ Although mortality from acute overdose of antipsychotic is uncommon, deliberate self-poisoning with antipsychotics was associated with an increased risk of death subsequently. ${ }^{23}$

\section{Valproic acid}

Valproic acid (VPA) is classically used as an anticonvulsant. It is also used as a mood stabiliser for bipolar affective disorder and other psychiatric indications. An overdose of $<100 \mathrm{mg} / \mathrm{kg}$ is unlikely to cause significant toxicity, but a dose of $>400 \mathrm{mg} / \mathrm{kg}$ can cause severe or life-threatening symptoms. As VPA commonly formulated as sustained release preparations, the onset of toxicity can be delayed. The commonest toxic feature is CNS depression that ranges from mild lethargy to deep coma and respiratory depression. In severe cases, cerebral oedema and death can occur. Hyperammonaemia, with or without hepatotoxicity, is associated with VPA in both therapeutic and overdose situations and may cause CNS toxicity. GI symptoms (nausea, vomiting, and abdominal pain) and cardiovascular features (hypotension and tachycardia) may also occur. Blood VPA concentration correlates with clinical toxicity, serial VPA levels, and blood ammonia level, and is useful for investigating VPA poisoning. ${ }^{24}$ In addition to supportive care and GI decontamination, L-carnitine and naloxone are antidotes for VPA poisoning. L-carnitine is effective in treating VPA-induced hyperammonaemia, encephalopathy, and hepatotoxicity. ${ }^{25}$ Intravenous L-carnitine can be given at a dose of $50 \mathrm{mg} / \mathrm{kg}$ every $8 \mathrm{~h}$ for $24 \mathrm{~h}$ and then reassessment for further doses. Intravenous naloxone can reverse CNS and respiratory depression. ${ }^{26}$ Extracorporeal treatment is useful to enhance valproate clearance and should be considered in severe poisoning cases presented with coma, cerebral oedema, respiratory depression requiring mechanical ventilation, shock, significant hyperammonaemia, metabolic acidosis with $\mathrm{pH}<7.1$, or a VPA blood concentration of $>900 \mathrm{mg} / \mathrm{L}(>6250 \mu \mathrm{mol} / \mathrm{L}){ }^{27}$

\section{Lithium}

Lithium is used for treatment of bipolar disorder. It is almost $100 \%$ renal excreted; its elimination half-life averages 20 to 24 hours in patients with normal renal function and may be significantly prolonged in patients with reduced glomerular filtration rate or with conditions that increase proximal tubule reabsorption rate. Three types of lithium overdose are encountered clinically. For single acute overdose in patients not on lithium, toxicity is unlikely when $<50 \mathrm{mg} / \mathrm{kg}$ lithium carbonate is ingested. Toxicity is usually mild although delayed toxicity may occur in massive ingestion or renal impairment. For acute on chronic overdose, a small amount overdose may cause severe toxicity in patients on lithium therapy. For chronic overdose, the onset of toxicity is gradual and progressive. Clinical features of lithium poisoning are non-specific, with neuropsychiatric features predominate. GI symptoms such as nausea or vomiting are more prominent for patients with acute overdose. CNS toxicities include tremors, hyperreflexia, agitation, ataxia, seizures, myoclonus, and coma. Cardiovascular toxicities include non-specific T-wave changes and prolonged QTc in electrocardiography, bradycardia, and hypotension. Management begins with supportive care, including measures to ensure adequate urine output. Activated 
charcoal has no role in lithium poisoning. ${ }^{28}$ Gastric lavage or whole bowel irrigation can be considered in severe cases. Extracorporeal treatment, preferably by haemodialysis, is indicated in those with coma, seizure, life-threatening arrhythmia with supratherapeutic serum lithium level, or a lithium level of $>4 \mathrm{mmol} / \mathrm{L}^{29}$

\section{Methylphenidate}

Methylphenidate is used to treat attention deficit hyperactivity disorder and narcolepsy. The reasons of methylphenidate poisoning include unintentional ingestion, suicidal attempt, and intentional misuse or abuse. Methylphenidate is available in immediate-release or modified-release formulations with the peak plasma concentration at $2 \mathrm{~h}$ and 6-8 $\mathrm{h}$ after ingestion, respectively. Methylphenidate blocks dopamine and norepinephrine transporters in the brain, thereby inhibiting dopamine and norepinephrine recycling, resulting in increased levels of these neurotransmitters. Toxicity is not expected at a dose $<1 \mathrm{mg} / \mathrm{kg}$. No severe toxicity was observed in patients who ingested $<3 \mathrm{mg} / \mathrm{kg} .{ }^{30}$ Common features in overdose are nausea, headache, agitation, confusion, mydriasis, tachycardia, and hypertension. ${ }^{31}$ Severe symptoms such as convulsion, coma, and arrhythmia may occur in large amount overdose. Serotonin syndrome may also occur. Supportive care and GI decontamination in selected cases are the mainstay treatment. Hypertension can be initially treated with benzodiazepines to control agitation. Alpha adrenergic receptor antagonists (such as phentolamine) and short-acting vasodilators (such as nitroprusside and nitroglycerine) are second-line agents for severe hypertension. Beta-blockers are generally not suggested because of their unopposed alpha stimulation effect. There is no specific antidote. Extracorporeal treatment is not effective owing to its large volume of distribution.

\section{Conclusion}

Psychiatric medication overdose contributes a significant proportion of poisoning cases in Hong Kong. The clinical approach emphasises on patient assessment, supportive measures, and individual consideration for decontamination, antidote use, and enhanced elimination. Input from clinical toxicologist is advised in managing poisoning cases.

\section{References}

1. Hong Kong Academy of Medicine: Recognition of Specialties. Available from: https://www.hkam.org.hk/HKAMWEB/pages_3_64. html. Accessed 29 January 2018.

2. Chan YC, Tse ML, Lau FL. Hong Kong Poison Information Centre: Annual Report 2006. Hong Kong J Emerg Med 2006;15:240-53. Crossref

3. Chan YC, Chan CK, Ng CH, Ng SH, Lau KK, Tse ML. Hong Kong Poison Information Centre: Annual Report 2016. Hong Kong J Emerg Med 2016;24:244-54. Crossref

4. Benson BE, Hoppu K, Troutman WG, Bedry R, Erdman A, Höjer $\mathrm{J}$, et al. Position paper update: gastric lavage for gastrointestinal decontamination. Clin Toxicol (Phila) 2013;51:140-6. Crossref

5. Chyka PA, Seger D, Krenzelok EP, Vale JA; American Academy of
Clinical Toxicology; European Association of Poisons Centres and Clinical Toxicologists. Position paper: single-dose activated charcoal. Clin Toxicol (Phila) 2005;43:61-87. Crossref

6. Position statement and practice guidelines on the use of multi-dose activated charcoal in the treatment of acute poisoning. American Academy of Clinical Toxicology; European Association of Poisons Centres and Clinical Toxicologists. J Toxicol Clin Toxicol 1999;37:73151. Crossref

7. Thanacoody R, Caravati EM, Troutman B, Höjer J, Benson B, Hoppu K, et al. Position paper update: whole bowel irrigation for gastrointestinal decontamination of overdose patients. Clin Toxicol (Phila) 2015;53:5-12. Crossref

8. Eddleston M, Juszczak E, Buckley NA, Senarathna L, Mohamed F, Dissanayake W, et al. Multiple-dose activated charcoal in acute self-poisoning: a randomised controlled trial. Lancet 2008;371:57987. Crossref

9. Olson KR. Activated charcoal for acute poisoning: one toxicologist's journey. J Med Toxicol 2010;6:190-8. Crossref

10. Lavergne V, Nolin TD, Hoffman RS, Roberts D, Gosselin S, Goldfarb DS, et al. The EXTRIP (EXtracorporeal TReatments In Poisoning) workgroup: guideline methodology. Clin Toxicol (Phila) 2012;50:40313. Crossref

11. Kung SW, Tse ML, Chan YC, Lau FL, Tsui SH, Tam S, et al. Zopiclone-associated methemoglobinemia and renal impairment. Clin Toxicol (Phila) 2008;46:1099-100. Crossref

12. Cienki JJ, Bukhart KK, Donovan JW. Zopiclone overdose responsive to flumazenil. Clin Toxicol (Phila) 2005;43:385-6. Crossref

13. Boehnert MT, Lovejoy FH Jr. Value of the QRS duration versus the serum drug level in predicting seizures and ventricular arrhythmias after an acute overdose of tricyclic antidepressants. N Engl J Med 1985;313:474-9. Crossref

14. Bebarta VS, Phillips S, Eberhardt A, Calihan KJ, Waksman JC, Heard $\mathrm{K}$. Incidence of Brugada electrocardiographic pattern and outcomes of these patients after intentional tricyclic antidepressant ingestion. Am J Cardiol 2007;100:656-60. Crossref

15. Agarwala R, Ahmed SZ, Wiegand TJ. Prolonged use of intravenous lipid emulsion in a severe tricyclic antidepressant overdose. J Med Toxicol 2014;10:210-4. Crossref

16. Cao D, Heard K, Foran M, Koyfman A. Intravenous lipid emulsion in the emergency department: a systematic review of recent literature. J Emerg Med 2015;48:387-97. Crossref

17. Holger JS, Engebretsen KM, Marini JJ. High dose insulin in toxic cardiogenic shock. Clin Toxicol (Phila) 2009;47:303-7. Crossref

18. Yates C, Galvao T, Sowinski KM, Mardini K, Botnaru T, Gosselin S, et al. Extracorporeal treatment for tricyclic antidepressant poisoning: recommendations from the EXTRIP Workgroup. Semin Dial 2014;27:381-9. Crossref

19. Whyte IM, Dawson AH, Buckley NA. Relative toxicity of venlafaxine and selective serotonin reuptake inhibitors in overdose compared to tricyclic antidepressants. QJM 2003;96:369-74. Crossref

20. Isbister GK, Bowe SJ, Dawson A, Whyte IM. Relative toxicity of selective serotonin reuptake inhibitors (SSRIs) in overdose. J Toxicol Clin Toxicol 2004;42:277-85. Crossref

21. Boyer EW, Shannon M. The serotonin syndrome. N Engl J Med 2005;352:1112-20. Crossref

22. Trollor JN, Chen X, Sachdev PS. Neuroleptic malignant syndrome associated with atypical antipsychotic drugs. CNS Drugs 2009;23:47792. Crossref

23. Toft S, Horwitz H, Dalhoff KP. Long-term mortality after poisoning with antipsychotics. Clin Toxciol (Phila) 2017;55:267-74. Crossref

24. Spiller HA, Krenzelok EP, Klein-Schwartz W, Winter ML, Weber JA, Sollee DR, et al. Multicenter case series of valproic acid ingestion: serum concentrations and toxicity. J Toxicol Clin Toxicol 2000;38:75560. Crossref

25. Bohan TP, Helton E, McDonald I, König S, Gazitt S, Sugimoto T, et al. Effect of L-carnitine treatment for valproate-induced hepatotoxicity. Neurology 2001;56:1405-9. Crossref

26. Roberge RJ, Francis EH 3rd. Use of naloxone in valproic acid 
overdose: case report and review. J Emerg Med 2002;22:67-70. Crossref

27. Ghannoum M, Laliberté M, Nolin TD, MacTier R, Lavergne V, Hoffman RS, et al. Extracorporeal treatment for valproic acid poisoning: systematic review and recommendations from the EXTRIP workgroup. Clin Toxicol (Phila) 2015;53:454-65. Crossref

28. Waring WS. Management of lithium toxicity. Toxicol Rev 2006;25:22130. Crossref

29. Decker BS, Goldfarb DS, Dargan PI, Friesen M, Gosselin S, Hoffman RS, et al. Extracorporeal treatment for lithium poisoning: systematic review and recommendations from the EXTRIP workgroup. Clin J Am Soc Nephrol 2015;10:875-87. Crossref

30. Rietjens SJ, Hondebrink L, Jorna T, de Vries I. Methylphenidate poisoning: relatively mild symptoms even after high-dose exposure. Clin Toxicol (Phila) 2017;55:941-2. Crossref

31. Hondebrink L, Rietjens SJ, Hunault CC, Pereira RR, Kelleci N, Yasar G, et al. Methylphenidate intoxications in children and adults: exposure circumstances and evidence-based dose threshold for prehospital triage. Clin Toxicol (Phila) 2015;53:168-77. Crossref 